pag

Business School

WORKING PAPER SERIES

\begin{tabular}{|l|l} 
Working Paper & $\begin{array}{l}\text { Exchange rate movements and stock } \\
\text { market returns in a regime-switching } \\
\text { environment: Evidence for BRICS } \\
\text { countries }\end{array}$ \\
& $\begin{array}{l}\text { Walid Chkili } \\
\text { Duc Khuong Nguyen }\end{array}$
\end{tabular}

http://www.ipag.fr/fr/accueil/la-recherche/publications-WP.html

IPAG Business School

184, Boulevard Saint-Germain

75006 Paris

France

IPAG working papers are circulated for discussion and comments only. They have not been peer-reviewed and may not be reproduced without permission of the authors. 


\title{
Exchange rate movements and stock market returns in a regime- switching environment: Evidence for BRICS countries
}

\author{
Walid Chkili \\ International Finance Group, Tunisia and Faculty of Economics and Management of Mahdia, Univer- \\ sity of Monastir, Tunisia \\ Email: walidchkili@fsegt.rnu.tn
}

\section{Duc Khuong Nguyen}

IPAG Lab, IPAG Business School, France

Email: duc.nguyen@ipag.fr

\begin{abstract}
We use a regime-switching model approach to investigate the dynamic linkages between the exchange rates and stock market returns for the BRICS countries (Brazil, Russia, India, China and South Africa). The univariate analysis indicates that stock returns of the BRICS countries evolve according to two different regimes: a low volatility regime and a high volatility regime. On the other hand, our evidence from Markov switching VAR models suggests that stock markets have more influence on exchange rates during both calm and turbulent periods. These empirical insights have important implications for portfolio investments and currency risk hedging.
\end{abstract}

JEL classification: C22, G15, F31

Keywords: Stock markets, Foreign exchange rate, BRICS countries, Markov switching VAR 


\section{Introduction}

The dynamic linkages between stock prices and exchange rate movements have attracted a special attention from both academics and practitioners. A strong relationship between them would have important implications for economic policies and international capital budgeting decisions because negative shocks affecting one market may be transmitted quickly to another through contagious effects. This issue has become more critical with the occurrence of recent black swan events such as the US 2007 subprime crisis and the "Great Depression" of 2008. The existing literature in financial economics has provided two potential theoretical explanations for the interactions between stock prices and exchange rates. On the one hand, the earlier study by Dornbusch and Fisher (1980) shows, from a flow-oriented model, that domestic currency depreciation improves the competiveness of local firms, which in turn leads to increase their exports and future cash flows. As a result, stock prices will move up in response to the increase in expected cash flows. On the other hand, the stock-oriented models of exchange rate determination (also called the portfolio balance approach) establish a directional impact from stock prices to exchange rates (Branson, 1983; Frankel, 1983). Indeed, the movements in exchange rates may be driven by the changes in stock prices through the exchange rate adjustments to the changes in supply and demand of foreign and domestic assets in internationally diversified portfolios.

The empirical evidence on the stock price - exchange rate relationships has been document by numerous studies. For example, Yang and Doong (2004) find that stock market movements have a significant impact on future exchange rate changes for the $\mathrm{G} 7$ countries over the period 1979-1999. More interestingly, they note that stock markets contain a more important informative content than foreign exchange markets. Phylaktis and Ravazolo (2005) show, from applying the cointegration methodology and multivariate Granger causality test to a group of Pacific Basin countries, that stock and foreign exchange markets are positively linked. Pan et al. (2007) use a VAR approach to analyze the links between exchange rates and stock markets for seven East Asian countries, and provide evidence of a significant bidirectional relationship between these markets before the Asian financial crisis. More recently, Chkili et al. (2011) use a Markov-Switching EGARCH model to investigate the dynamic relationships between exchange rates and stock returns in four emerging countries (Hong Kong, Singapore, Malaysia and Mexico) during both normal and turbulent periods. They provide evidence of regimedependent links and asymmetric responses of stock market volatility to shocks affecting foreign exchange market. Diamandis and Drakos (2011) examine the long-run and short-run dy- 
namics between stock and foreign exchange markets for four Latin American countries (Argentina, Brazil, Chile and Mexico), as well as their interactions with the U.S. stock markets. These authors find that the two markets in these economies are positively related and the U.S. stock market represents a transmission channel for these links. Lin (2012) adopts a similar approach to investigate the comovement between exchange rates and stock prices for several Asian emerging markets, and shows evidence of stronger comovement during crisis periods, after some economic and policy events such as market openings and crises are accounted for.

In this article we also examine the dynamic linkages between stock markets and foreign exchange (FX) markets. Our focus is on the BRICS countries (Brazil, Russia, India, China, and South Africa) which represent, during the two last decades, the most advanced emerging countries in terms of economic growth and stock market development. The results from our study interest not only policymakers who are concerned by contagious effects and better regulations of these markets to promote economic growth, but also investors and fund managers who seek to hedge their investment risks in the BRICS countries. Specifically, a Markov switching vector autoregressive model (MS-VAR) is used to detect the interactions between stock and FX markets over the turbulent period 1997-2013. Our study period thus covers the world's major crises in the past two decades (e.g., the Asian financial crisis, the Russian and Brazilian crises, the 2007 subprime crisis, the global financial crisis 2008-2009, and the European debt crisis 2010-2011). The presence of these crises justifies entirely our choice of regime-switching models because, as discussed in subsequent sections, the stock and FX markets in the BRICS countries are effectively linked to each other in a regime-shift environment.

The remainder of this article is organized as follows. Section 2 presents the Markov switching model used in this study. Section 3 describes the data. Section 4 reports and discusses the results. Section 5 concludes the article.

\section{The Markov switching model}

Following Hamilton (1989), a time-series variable $y_{t}$ can be modeled by a Markov switching autoregressive of order $p$ (MS-AR) with regime shifts in mean and variance as follows

$y_{t}=\mu\left(s_{t}\right)+\left[\sum_{i=1}^{P} \phi_{i}\left(y_{t-1}-\mu\left(s_{t-i}\right)\right)\right]+\sigma\left(s_{t}\right) \varepsilon_{t}$

where $\phi_{i}$ are the autoregressive coefficients. $\mu$ and $\sigma$ are the mean and standard deviation depending on the regime $S_{t}$ at time $t . y_{t}$ represents the stock market returns of the BRICS coun- 
tries. This MS-AR framework allows us to not only detect potential regime shifts in the stock market returns, but also investigate the impact of crises on the stock market volatility.

As we are concerned by the relationships between stock and FX markets in the BRICS countries, the MS-VAR model developed by Krolzig (1997) is a suitable approach. This model is a generalization of the MS-AR model of Hamilton (1989) we presented above. The MS-VAR model can be written as follows

$$
\begin{aligned}
& r_{t}=\alpha_{1}+\sum_{k=1}^{l} \alpha_{2 j}\left(s_{t}\right) r_{t-k}+\sum_{k=1}^{l} \alpha_{3 j}\left(s_{t}\right) e_{t-k}+v\left(s_{t}\right) u_{r, t} \\
& e_{t}=\beta_{1}+\sum_{k=1}^{l} \beta_{2 j}\left(s_{t}\right) e_{t-k}+\sum_{k=1}^{l} \beta_{3 j}\left(s_{t}\right) r_{t-k}+v\left(s_{t}\right) u_{e, t}
\end{aligned}
$$

where $r_{t}$ and $e_{t}$ denote the stock market and exchange rate returns for each country, respectively. $u_{t}$ is the innovation process with a variance $v\left(s_{t}\right)$ depending on regime $S_{t}$ which is assumed to follow an irreducible ergodic two-state Markov process, defined by the transition probabilities $p_{i j}$ between states as follows ${ }^{1}$ :

$$
P_{i j}=P\left[S_{t}=j / S_{t-1}=i\right] \text { with } \sum_{j=1}^{2} P_{i j}=1 \text { for all } i, j \in\{1,2\}
$$

where

$$
\left\{\begin{array}{l}
P_{11}=P\left(S_{t}=1 \mid S_{t-1}=1\right) \\
P_{12}=1-P_{11}=P\left(S_{t}=1 \mid S_{t-1}=2\right) \\
P_{21}=1-P_{22}=P\left(S_{t}=2 \mid S_{t-1}=1\right) \\
P_{22}=P\left(S_{t}=2 \mid S_{t-1}=2\right)
\end{array}\right.
$$

Overall, the MS-VAR model is flexible enough to capture the potential of regime shifts in the data generating processes of stock and exchange rate returns, to the extent that financial markets have experienced several periods of important instabilities and long swings over the last three decades. Ignoring the importance of structural breaks in explaining the dynamics of stock returns and exchange rates may lead to misleading conclusions about their time-varying behavior and interactions. Krolzig (2000) notes that taking the regime-switching feature of economic processes into account might lead to better forecasting devices than time-invariant linear models and traditional robustifying methods (e.g., differencing, intercept correction and multistep estimation) in case where breaks recur in a systematic and stochastic pattern.

\footnotetext{
${ }^{1}$ Hamilton (1994) reviews the theory of Markov chains with application to Markov-switching models, and note that the assumptions of irreducibility and ergodicity are essential for the theoretical properties of MS-VAR models.
} 


\section{Data}

Our dataset consists of weekly stock prices and US dollar exchange rates for the BRICS countries (Brazil, Russia, India, China and South Africa). The sample period spans from March 1997 to February 2013, yielding a total of 832 observations. Stock market data are extracted from Datastream International and are expressed in local currencies. Exchange rate series are obtained from the Pacific exchange rate database and represent the amount of US dollars per one unit of local currency. The weekly continuously compounded returns are computed by taking the difference in the logarithm of two consecutive prices.

Table 1 reports summary statistics and unit root tests for the return series. On average, stock market returns are higher than the returns on exchange rates for all countries, but they are more volatile as indicated by the associated standard deviations. The stock market in South Africa is the least volatile (2.913\%) among the stock markets of the BRICS, while the Russian stock market is the most volatile (6.370\%). The exchange rate volatility varies between 0.129 $\%$ for China and $2.388 \%$ for Russia.

We also perform the Augmented Dickey-Fuller unit root test and report the results in the last column of Table 1 . We see that all the return series are stationary at the $1 \%$ significance level. They are thus appropriate for further statistical analysis.

Table 1

Descriptive statistics and unit root tests

\begin{tabular}{|c|c|c|c|c|c|c|c|}
\hline & Mean $(\%)$ & Std. Dev. (\%). & Skewness & Kurtosis & JB & $\mathrm{LB}^{2}$ & $\mathrm{ADF}$ \\
\hline \multicolumn{8}{|c|}{ Panel A: stock returns } \\
\hline Brazil & 0.215 & 4.554 & -0.575 & 6.686 & $516.9^{*}$ & $177.02^{*}$ & $-18.835^{*}$ \\
\hline Russia & 0.193 & 6.370 & -0.447 & 7.175 & $631.94^{*}$ & $462.34^{*}$ & $-17.419^{*}$ \\
\hline India & 0.183 & 3.586 & -0.345 & 5.002 & $152.43^{*}$ & $102.76^{*}$ & $-18.217^{*}$ \\
\hline China & 0.092 & 3.388 & 0.052 & 4.841 & $117.93^{*}$ & $146.65^{*}$ & $-26.933^{*}$ \\
\hline S. Africa & 0.209 & 2.913 & -0.438 & 7.478 & $720.96^{*}$ & $208.42^{*}$ & $-28.813^{*}$ \\
\hline \multicolumn{8}{|c|}{ Panel B: exchange rate changes } \\
\hline & Mean $(\%)$ & Std. Dev. (\%) & Skewness & Kurtosis & JB & $\mathrm{LB}^{2}$ & ADF \\
\hline Brazil & 0.075 & 2.036 & 2.890 & 28.337 & $23414.6^{*}$ & $226.55^{*}$ & $-22.632^{*}$ \\
\hline Russia & 0.200 & 2.388 & 9.788 & 139.78 & $661858^{*}$ & $310.10^{*}$ & $-10.876^{*}$ \\
\hline India & 0.051 & 0.742 & -0.217 & 8.839 & $1165.7^{*}$ & $272.53^{*}$ & $-21.642^{*}$ \\
\hline China & -0.034 & 0.129 & -2.340 & 18.339 & $8916.1^{*}$ & $159.89^{*}$ & $-20.568^{*}$ \\
\hline S. Africa & 0.084 & 1.877 & 0.966 & 6.745 & $614.84^{*}$ & $199.64^{*}$ & $-23.317^{*}$ \\
\hline
\end{tabular}

Notes: JB is the Jarque-Bera test statistics for normality. $\mathrm{LB}^{2}$ is the empirical statistics of the Ljung-Box test for autocorrelation applied to squared returns of order 12. ADF is the Augmented Dickey-Fuller unit root tests. ${ }^{*}$ indicates that the null hypothesis is rejected at the $1 \%$ level. 


\section{Results}

\subsection{Regime shifts in the stock markets of BRICS countries}

Since our study aims to examine the relationships between stock and exchange markets in a regime-switching environment, the first step in our empirical investigation consists of verifying whether stock returns of sample markets exhibit regime-switching behavior. For this purpose, we proceed to test the null hypothesis of no regime shifts (i.e., the dynamics of stock returns is better reproduced by a linear autoregressive model) against the alternative of regime switching model which corresponds to a MS-AR model. Formally, the likelihood ratio test (LR) developed by Garcia and Perron (1996) is used to make final choice of suitable modeling approaches. This test is computed as follows

$$
L R=2 \times\left|\ln L_{M S-A R}-\ln L_{A R}\right|
$$

where $\ln L$ is the log likelihood of the competing models. The best-suited model is selected on the basis of Davies (1987) critical values. As shown in Table 2, the LR test statistics are significant in all cases at the $1 \%$ level. These results lead us to reject the null hypothesis of no regime shifts for the stock markets in the BRICS countries, which means that the time-varying behavior of these markets is better described by the nonlinear MS-AR model. Past studies, including, among others, Kanas (2005), Wang and Theobald (2008), Chkili et al. (2012), and Chkili and Nguyen (2011), find similar results for other emerging markets. From a theoretical point of view, this behavior is expected and can be explained by the changing economic structure in these markets owing to structural economic reform policies (financial liberalization, tax system adjustments, competition policy) as well as the occurrence of successive economic and financial crises at both regional and international levels.

Table 2

LR test statistic results

\begin{tabular}{lccc}
\hline & $\ln L(\mathrm{AR})$ & $\ln L(\mathrm{MS}-\mathrm{AR})$ & $\mathrm{LR}$ \\
\hline Brazil & -2437.77 & -2351.21 & $173.12^{++}$ \\
Russia & -2714.82 & -2559.94 & $309.76^{++}$ \\
India & -2196.95 & -2133.36 & $127.18^{++}$ \\
China & -2190.68 & -2132.3 & $116.76^{++}$ \\
South Africa & -2065.09 & -1984.01 & $162.16^{++}$ \\
\hline
\end{tabular}

Notes: ${ }^{++}$denote the null hypothesis of no regime shift is rejected at the $1 \%$ significance level.

The MS-AR models are then estimated for each of the sample stock markets and the estimation results are reported in Table 3. A close look at the standard deviations shows that they are highly significant for all markets and that their values clearly indicate the existence of two 
different regimes. The first regime, referred to as regime 1 , is characterized by a low volatility level and the second regime (regime 2) displays a high volatility level. For all cases, the volatility of regime 2 is at least two times higher than that of regime 1. Among the BRICS stock markets, Brazil and Russia have the highest volatility in both the low and high volatility regimes. Table 3 also indicates that the probability of being in regime 1 is higher than the probability of staying in regime 2, regardless of the markets. Indeed, the probability of being in the low volatility regime 1 ranges from 0.959 (South Africa) to 0.988 (Brazil), while the probability of being in high volatility regime is comprised between 0.843 (South Africa) and 0.980 (India). The magnitude of these probabilities $\left(P_{11}\right.$ and $\left.P_{22}\right)$ suggests that the low volatility regime is more persistent than the high volatility one, or in other words, the stock markets of BRICS countries stay longer in regime 1 than in regime 2 . This finding is fully confirmed by the average duration in weeks for each regime $\left(d_{1}\right.$ and $\left.d_{2}\right)$. The results show that the low volatility regime lasts, on average, between 82.33 weeks in Brazil and 24.39 weeks in South Africa. On the other hand, the average duration of the high volatility regime is 50 weeks in India, followed by 25.64 weeks in Russia, 17.86 weeks in China, 13.71 weeks in Brazil, and 6.37 weeks in South Africa.

Table 3

Estimation results for the MS-AR model

\begin{tabular}{lccccc}
\hline & Brazil & Russia & India & China & South Africa \\
\hline Const $(1)$ & $0.440^{* * *}(0.130)$ & $0.774^{* * *}(0.224)$ & $0.526^{* * *}(0.136)$ & $-0.105(0.136)$ & $0.498^{* * * *}(0.103)$ \\
Const(2) & $-1.097(0.974)$ & $-0.921^{*}(0.773)$ & $-0.220(0.266)$ & $0.358(0.297)$ & $-0.892^{*}(0.495)$ \\
AR1 & $-0.066^{* *}(0.032)$ & $0.069^{*}(0.041)$ & $0.054(0.039)$ & $0.062^{*}(0.037)$ & $-0.013(0.037)$ \\
$\sigma_{1}^{2}$ & $3.465^{* * *}(0.098)$ & $3.511^{* * *}(0.189)$ & $2.337^{* * *}(0.109)$ & $2.176^{* * *}(0.124)$ & $2.048^{* * *}(0.131)$ \\
$\sigma_{2}^{2}$ & $8.341^{* * *}(0.769)$ & $9.571^{* * *}(0.694)$ & $4.617^{* * *}(0.225)$ & $4.563^{* * *}(0.252)$ & $4.832^{* * *}(0.709)$ \\
$P_{11}$ & 0.988 & 0.980 & 0.983 & 0.960 & 0.959 \\
$P_{22}$ & 0.932 & 0.961 & 0.980 & 0.944 & 0.843 \\
$d_{1}$ & 82.33 & 50 & 58.82 & 25 & 24.39 \\
$d_{2}$ & 13.71 & 25.64 & 50 & 17.86 & 6.37 \\
$\log L$ & -2351.21 & -2559.94 & -2133.36 & -2132.3 & -1984.01 \\
$\mathrm{Q}^{2}(11)$ & $14.665[0.198]$ & $10.083[0.523]$ & $13.627[0.432]$ & $25.822[0.007]$ & $29.19[0.004]$ \\
\hline
\end{tabular}

Notes: standard deviations are reported in parentheses. $d_{l}$ and $d_{2}$ are the average durations for the stock market to be in regime 1 and in regime 2 , respectively. ${ }^{* * *},{ }^{* * *},{ }^{*}$ indicate that the estimated coefficients are significant at the $1 \%, 5 \%$ and $10 \%$ levels, respectively. $p$-values are given in brackets.

Figure 1 displays the stock market index, stock market returns and the smoothed probability of being in regime 2 for the five countries under consideration. The upper graphs show that the stock markets in the BRICS countries share several points in common. It can be noticed that they have had a low level during the 1990s and might not be attractive for both domestic 
and foreign investors. An upward trend is then observed, stating from the beginning of 2004 for all countries, except China where the increasing trend began in mid-2005. These stock markets experienced a sharp fall in 2009 , owing to the cumulative impact of the US subprime market and the subsequent global financial crisis. Afterwards, we see some signs of strong recovering, particularly in Brazil, Russia, and India. Overall, the time-variations in market indices suggest that the BRICS markets have not been decoupled from major external economic and financial shocks, and they tend to fluctuate strongly in response to these shocks.

The smoothed probability of staying in regime 2 (high volatility state), which is displayed in the middle graphs, shows several high volatility periods that are common to all markets. These periods cover particularly the episodes of the Asian and Latin American financial crisis from 1997 to 1999 as well as the US subprime and global financial crises from 2007 to 2009.

More specifically, the smoothed probability for the Brazilian stock market exhibits two important volatility peaks during the 1990s. The first peak corresponds to the Asian financial crisis (1997-1998), while the second coincides with the Russian and Brazilian financial crises of 1998-1999. The Brazilian market was also very volatile following the September 11, 2001 terrorist attack, during the Argentinean debt crisis of 2002 and finally throughout the subprime crisis. These strong responses to external shocks are not surprising because the Brazilian economy has become more integrated with the world economy and regional markets after the government embarked a series of structural reforms and financial liberalization in early 1980s (Bekaert and Harvey, 1995).

(a) Brazil
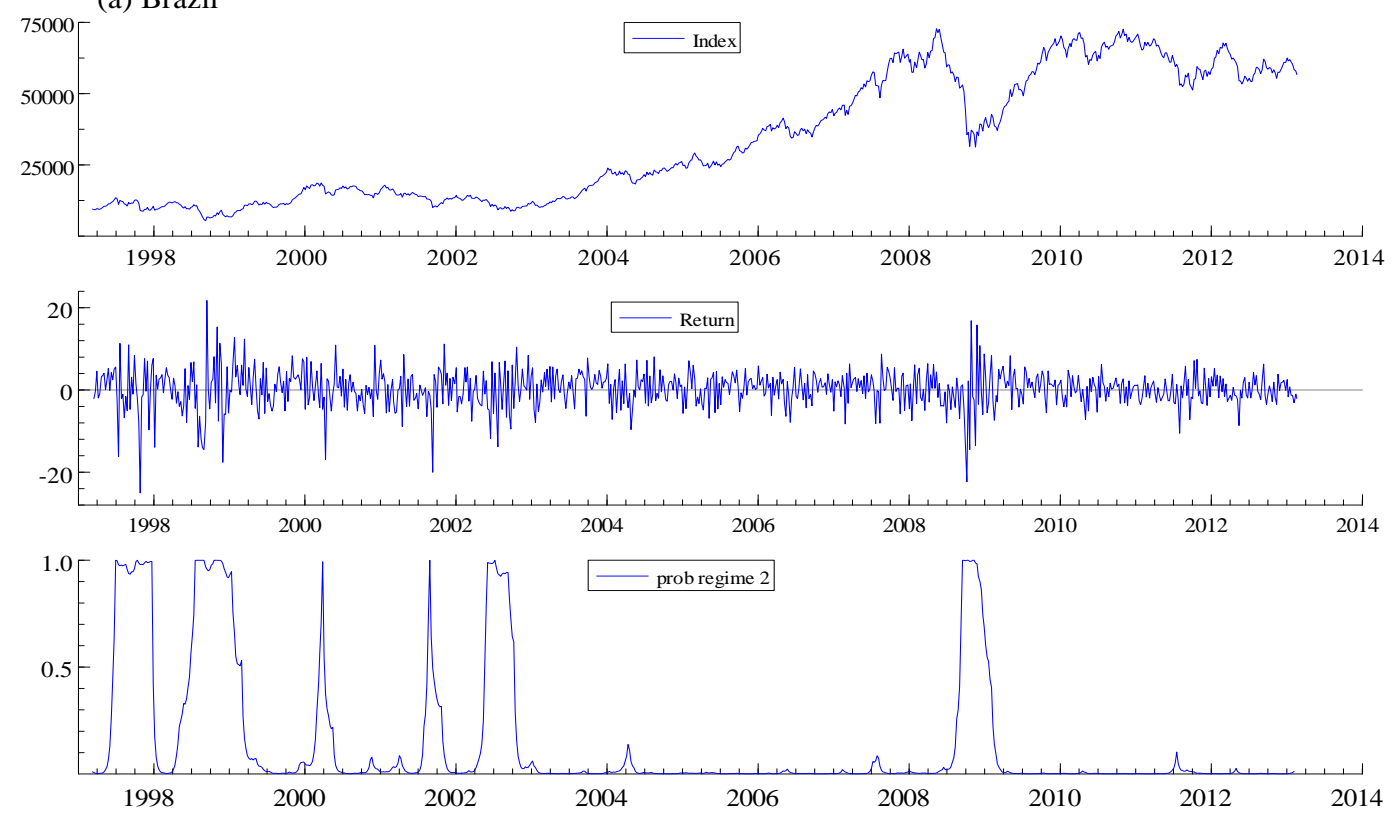
(b) Russia
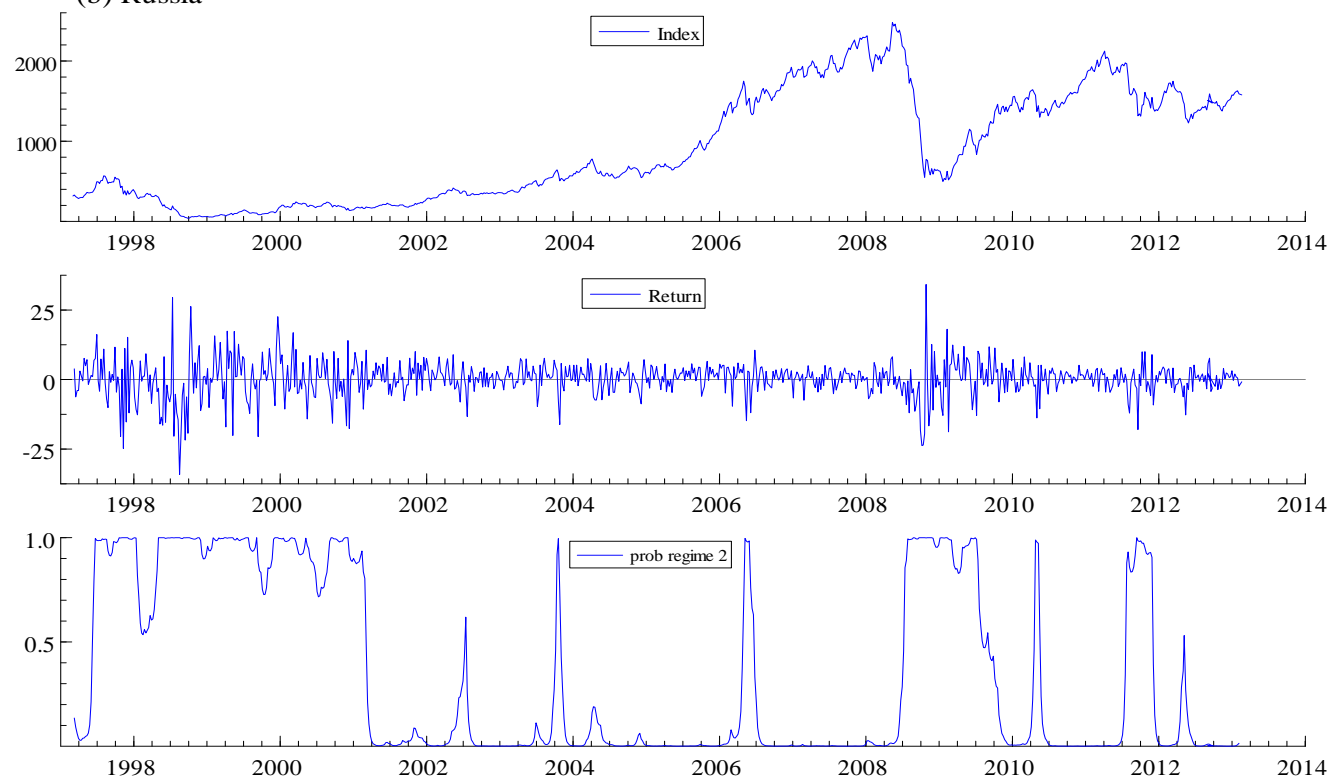

(c) India
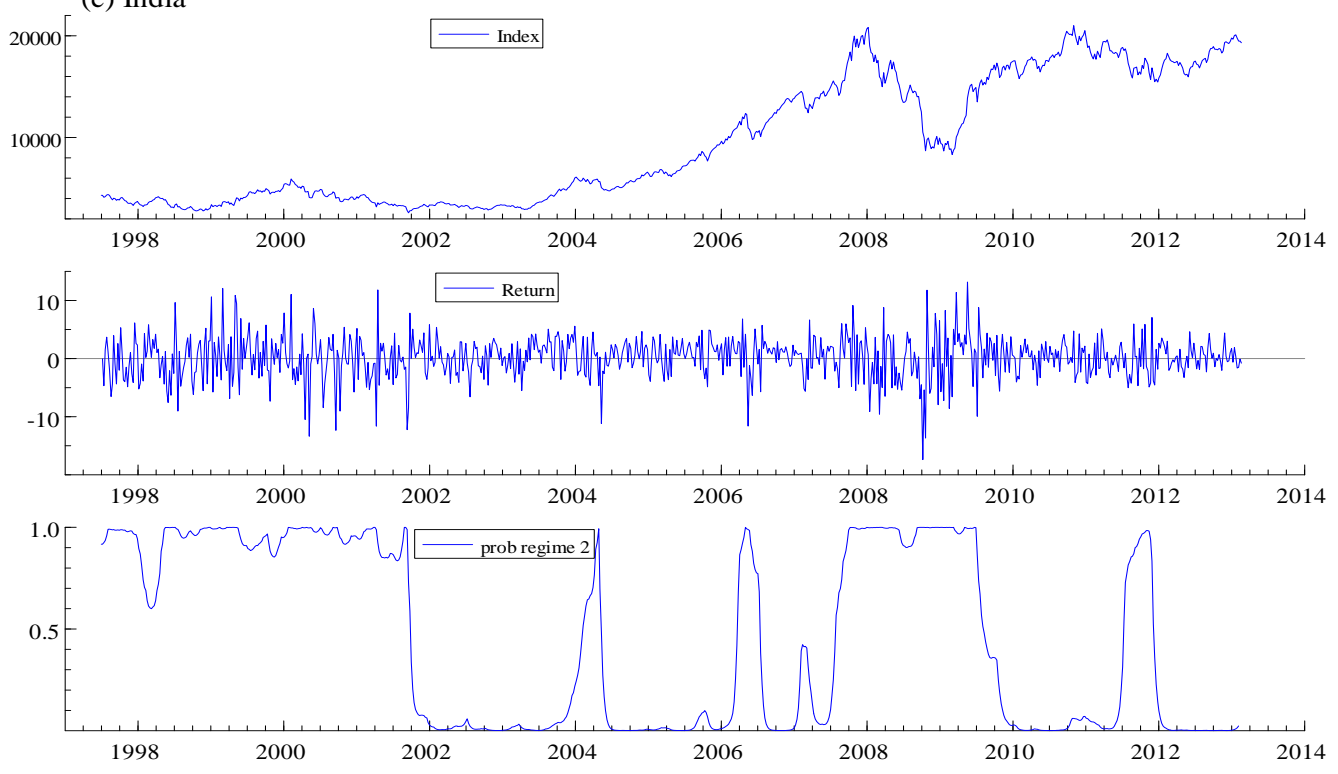

(d) China
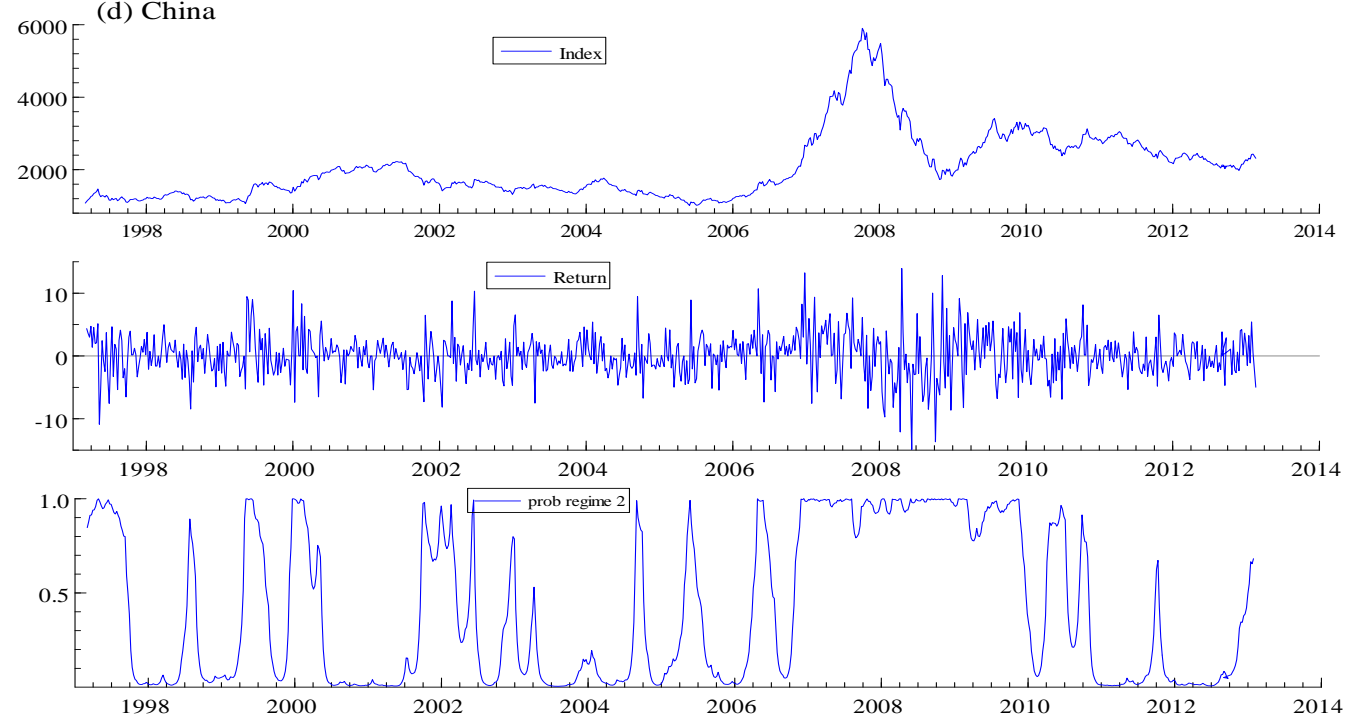
(e) South Africa
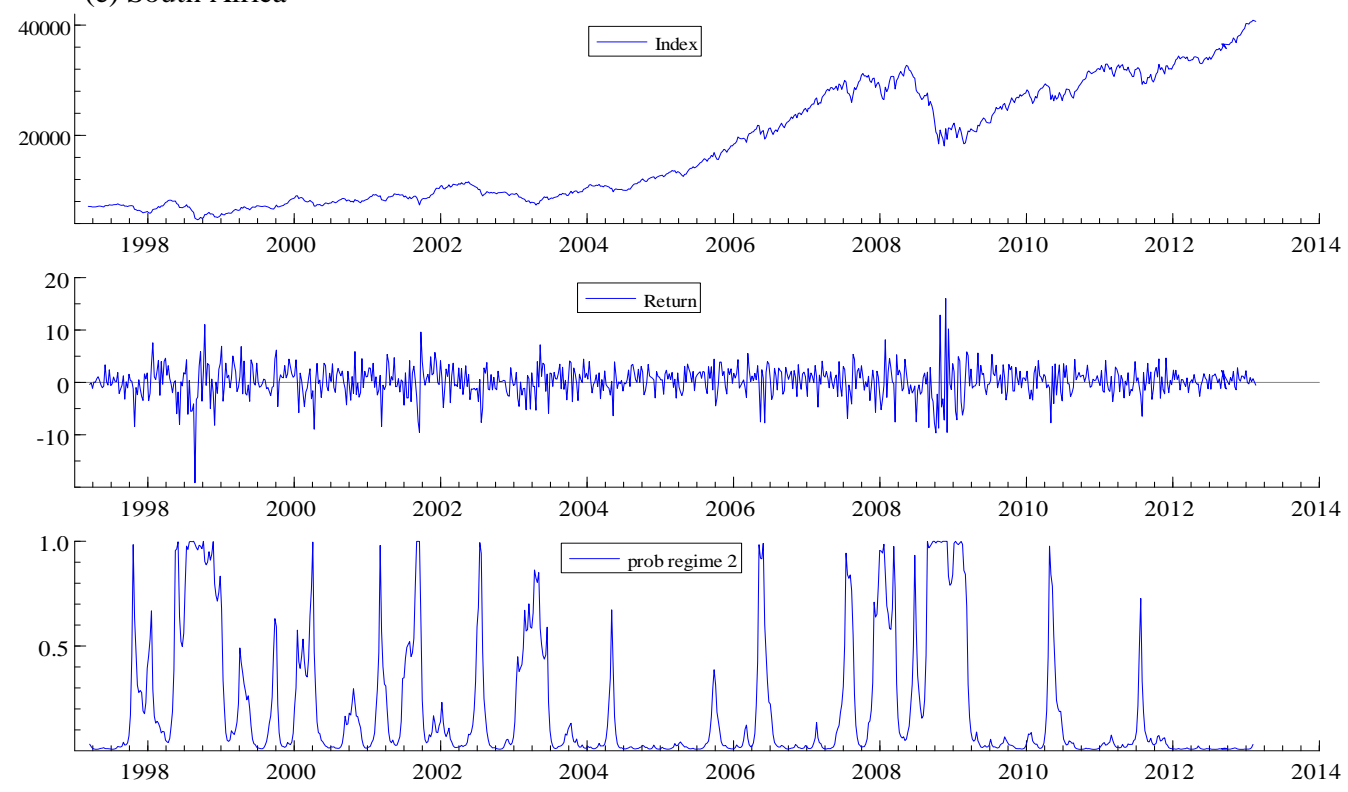

Figure 1: Stock market indices, stock market returns, and smoothed probability for high volatility regime

We find a quite similar pattern in the regime shifts for Russia and India since these two markets also entered into the high volatility regime in mid-1997 and stayed in this regime until the late of 2001 - a period which covers a series of several crises including the Asian crisis of 1997-1998, the Russian crisis of 1998 and the Brazilian crisis of 1999. The smoothed probability plots for regime 2 also detect two other episodes of high volatility, which coincide with the US subprime crisis and the global financial crisis between 2007 and 2010 as well as the 2011-2012 Greece's public debt crisis.

Finally, for China and South Africa, the estimated smoothed probability of being in regime 2 indicates that these markets frequently get in and out of the high volatility regime. They also reacted significantly to financial shocks following the advent of the Asian financial crisis and the Russian financial crisis. Significant increases in their volatility are also observed in the late 2001 as a result of the terrorist attack of September 11, 2001. Similarly, the return and volatility shocks from the subprime crisis and related black-swan events are equally transmitted to China and South Africa, which seems to explain their move to the high volatility regime in mid-2007. Other peaks of high volatility can be reasonably attributed to country-specific events and risk factors as stock returns are closely linked to the country's macroeconomic variables and business cycle.

\subsection{Exchange rate volatility}

This section examines the volatility of the US dollar exchange rates under consideration during the recent period marked by high economic and political uncertainty. Several studies sug- 
gest that the volatility of exchange rates in emerging countries is more pronounced during times of crises. For example, Coudert et al. (2011) investigate the impact of the recent global financial turmoil on the exchange rate volatility in emerging markets by analyzing its relationships to a global financial stress measure. After controlling for the potential of nonlinearities, they find that exchange rate volatility increases more than proportionally with the global financial stress, for most countries in their sample of 21 emerging countries over the period from January 1994 to September 2009. These authors also provide evidence of contagious effects from one emerging currency to other currencies in the neighboring area. The empirical evidence documented by Coudert et al. (2011) thus suggests that the US dollar exchange rates we consider may exhibit different behavior before and after major crises. To examine this hypothesis, we consider the volatility of exchange rates over the second half of the 1990s (March 1997-December 1999) and the late 2000s (July 2007-December 2009), respectively. The Asian financial crisis occurred in July 1997, while the Russian crisis happened in September 1998, and was followed by the Brazilian crisis in early 1999. The late 2000s is marked by the subprime mortgage crisis in 2007 that resulted in a global financial crisis. The tranquil period from January 2003 to May 2007 is also considered for comparison purpose. We use the squared weekly returns of exchange rates as proxy of their volatility. Figure 2 provides the effect of various crises on average exchange rate volatility. ${ }^{2}$

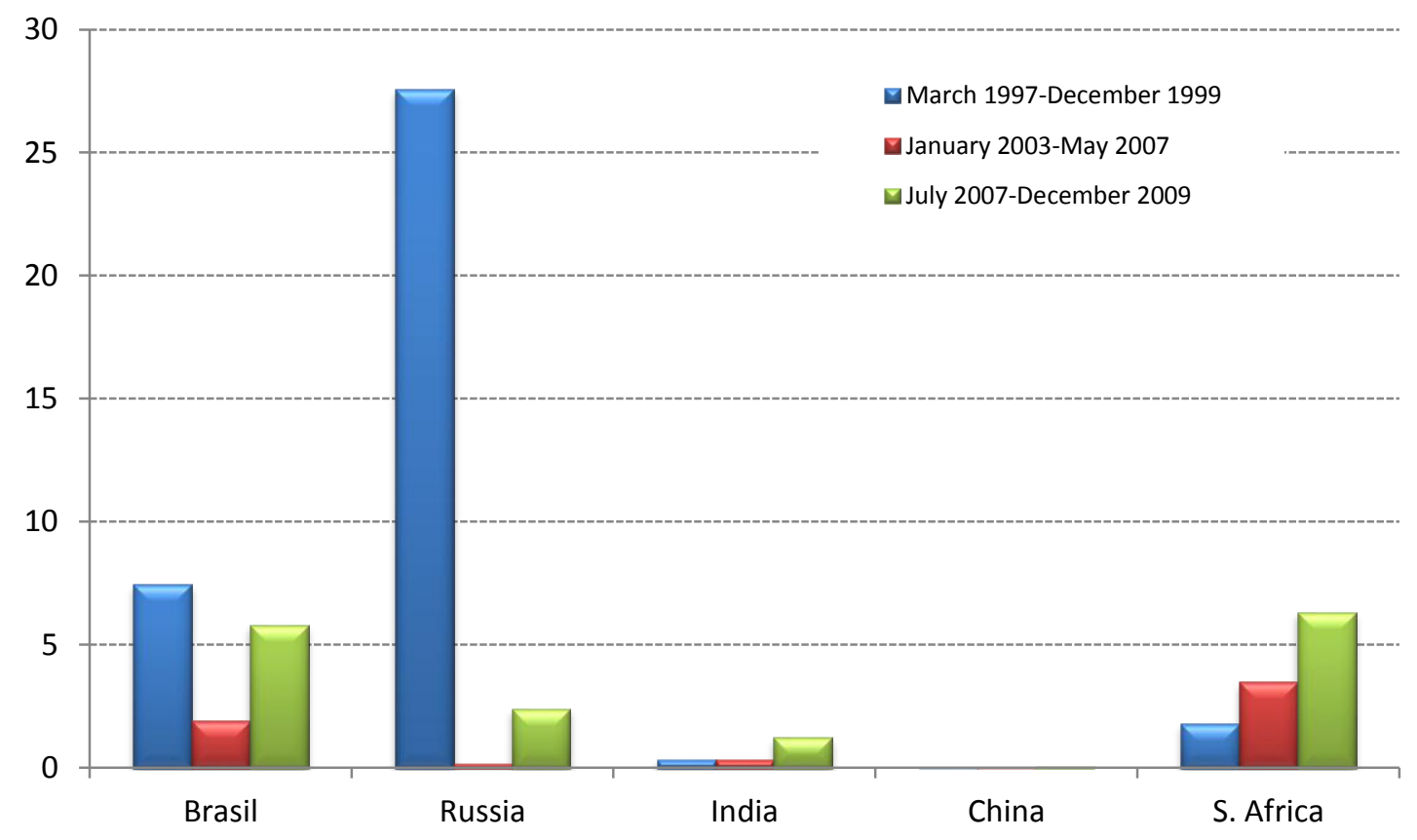

Figure 2: Exchange rate volatility $(\%)$ around the major crises

\footnotetext{
${ }^{2}$ The windows for pre- and post-crises used in our analysis appear in Figure 2.
} 
Figure 2 shows that the US dollar exchange rate of Chinese Yuan is the least volatile over the three considered periods, as compared with other countries' exchange rates. It also responded weakly to the major episodes of crises. Coudert et al. (2011) reach a similar conclusion and explain the very low level of exchange rate volatility for China by the hard peg of its currency to the US dollar through government interventions. This exchange rate policy has effectively caused a loss in China's foreign exchange reserves and a fall in the export competitiveness of local firms. The foreign exchange rate volatility of Indian Rupee against the US dollar was also limited in response to the series of crises that occurred during the late 1990s, but it increased slightly during the subprime and global financial crises. This result arises equally from the fact that the Indian Rupee is pegged against the US dollars.

As regards to the Russia Rubles, its exchange rate volatility was extremely sensitive to the series of crises that took place in the late 1990. This extremely high volatility happened at the time of the Russian crisis with a sharp increase in the financial stress. Figure 2 also shows that the exchange rate volatility for the Brazilian Real and the South African Rand significantly rose around the major crises of the last decades. However, the foreign exchange rate of Brazilian Real was more volatile over the period from 1997 to 1999, where Brazil's economy went into a deep recession. For its part, the exchange rate of South African Rand was particularly high during the period covering the US subprime crisis and global financial crisis. This increase in exchange rate volatility can be explained by the relative importance of the United States, as a main trade partner, towards the South African economy.

\subsection{Dynamic relationships between stock and foreign exchange markets}

Table 4 reports the estimation results for the MS-VAR model where the interactions between US dollar exchange rates and stock market returns in BRICS countries are explicitly analyzed. We begin with testing whether regime-switching behavior exists in the linkages of these markets, using the likelihood ratio (LR) tests. ${ }^{3}$ The results, presented in Panel A of Table 4, indicate that the LR tests reject the null hypothesis of no regime switching in the relationship between stock market and exchange rate returns in all cases. They thus imply that a MS-VAR model is suitable for reproducing the joint dynamics of these markets under the effects of regime shifts.

\footnotetext{
${ }^{3}$ The LR tests statistics are calculated as follows: $L R=2 \times\left|\ln L_{M S-V A R}-\ln L_{V A R}\right|$
} 
Table 4

Stock returns and exchange rate changes for BRICS countries: MS-VAR model

\begin{tabular}{|c|c|c|c|c|c|}
\hline & Brazil & Russia & India & China & South Africa \\
\hline \multicolumn{6}{|c|}{ Panel A: Regime switching tests } \\
\hline LR & $-391.4[0.00]$ & $632.72[0.00]$ & $559.78[0.00]$ & $781.18[0.00]$ & $-661.6[0.00]$ \\
\hline $\ln \mathrm{L}$ & -3040.2 & -2861.97 & -1940.41 & -2813.08 & -2825.9 \\
\hline & $\{-3235.9\}$ & $\{-3178.33\}$ & $\{-2220.3\}$ & $\{-3203.67\}$ & $\{-3156.7\}$ \\
\hline \multicolumn{6}{|c|}{ Panel B: Estimation results } \\
\hline$\alpha_{1}$ & $0.374^{\text {****** }}(0.125)$ & $0.535^{* * * * *}(0.148)$ & $0.335^{* * * *}(0.113)$ & $0.041(0.127)$ & $0.386^{\text {****** }}(0.096)$ \\
\hline$\alpha_{21}$ & $-0.089^{* *}(0.043)$ & $0.002(0.077)$ & $0.066(0.068)$ & $0.034(0.055)$ & $-0.026(0.075)$ \\
\hline$\alpha_{22}$ & $0.075(0.128)$ & $0.067(0.056)$ & $-0.001(0.064)$ & $0.105^{*}(0.055)$ & $0.045(0.113)$ \\
\hline$\alpha_{31}$ & $0.006(0.105)$ & $0.215(0548)$ & $0.509(1.818)$ & $4.441(13.43)$ & $0.027(0.063)$ \\
\hline$\alpha_{32}$ & $0.231(0.145)$ & $-0.038(0.036)$ & $-0.219(0.201)$ & $-1.152(0.935)$ & $0.180(0.165)$ \\
\hline$\beta_{1}$ & $-0.085(0.061)$ & $-0.012(0.021)$ & $-0.002(0.010)$ & $0.004(0.004)$ & $-0.059(0.084)$ \\
\hline$\beta_{21}$ & $0.171^{* * *}(0.045)$ & $0.302^{* * *}(0.088)$ & $0.302^{* *}(0.139)$ & $-0.365^{* * *}(0.067)$ & $0.185^{* * *}(0.065)$ \\
\hline$\beta_{22}$ & $0.281(0.178)$ & $0.028(0.084)$ & $0.186^{* * *}(0.068)$ & $-0.351^{* * * *}(0.067)$ & $0.264^{*}(0.161)$ \\
\hline$\beta_{31}$ & $-0.065^{* * *}(0.013)$ & $0.302^{* * *}(0.088)$ & $-0.005^{* * *}(0.002)$ & $-0.001(0.001)$ & $0.025(0.054)$ \\
\hline$\beta_{32}$ & $-0.038(0.074)$ & $-0.051^{* * *}(0.018)$ & $-0.050^{* * *}(0.011)$ & $0.004^{* *}(0.002)$ & $0.009(0.072)$ \\
\hline$P_{11}$ & 0.968 & 0.991 & 0.904 & 0.990 & 0.914 \\
\hline$P_{22}$ & 0.789 & 0.985 & 0.939 & 0.984 & 0.641 \\
\hline \multicolumn{6}{|c|}{ Correlation coefficient } \\
\hline Regime 1 & -0.395 & -0.168 & -0.044 & -0.003 & -0.125 \\
\hline Regime 2 & -0.583 & -0.522 & -0.704 & 0.107 & -0.411 \\
\hline \multicolumn{6}{|c|}{ Average duration } \\
\hline Regime 1 & 31.25 & 111.11 & 10.42 & 100 & 11.631 \\
\hline Regime 2 & 4.739 & 66.66 & 16.39 & 62.5 & 2.785 \\
\hline \multicolumn{6}{|c|}{ Std. Dev. of stock markets } \\
\hline Regime 1 & 3.597 & 4.252 & 3.107 & 2.874 & 2.125 \\
\hline Regime 2 & 8.935 & 6.152 & 3.557 & 3.579 & 5.485 \\
\hline \multicolumn{6}{|c|}{ Std. Dev. of foreign exchange market } \\
\hline Regime 1 & 1.182 & 0.297 & 0.107 & 0.174 & 1.417 \\
\hline Regime 2 & 4.789 & 1.884 & 0.838 & 0.011 & 3.368 \\
\hline
\end{tabular}

Regarding the estimation results of the MS-VAR model in Panel B, we can easily identify two regimes - a low volatility regime (regime 1) and a high volatility regime (regime 2) - with the former being more persistent than the latter. Indeed, the average duration of being in regime 1 is higher than in regime 2 for all sample countries. This result is consistent with the findings 
of Kanas (2005) and Chan et al. (2011). For instance, Kanas (2005) provides evidence of two regimes for the relationship between the Mexican exchange rate and the stock market returns of some emerging countries. Moreover, the results obtained by Kanas (2005) suggest that the low volatility regime is more persistent than the high volatility regime. Chan et al. (2011) reach the same conclusions when examining the return relationships across three different asset classes.

The results in Panel B also indicate that the estimated coefficients capturing the impact of exchange rate movements $\left(\alpha_{31}\right.$ and $\left.\alpha_{32}\right)$ on the stock market returns are not significant in all cases. This finding, which corroborate the result of previous studies (e.g., Kanas, 2000; Yang and Doong, 2004; Aloui, 2007), suggests that fluctuations in the US dollar exchange rates did not have strong effects on the dynamics of stock market returns. For example, Kanas (2000) examines the volatility spillover between exchange rates and stock markets for some developed countries, and documents that the volatility transmission from the foreign exchange markets to the stock markets is insignificant for all sample countries. Yang and Doong (2004) also find similar results for the G7 countries as they show that stock price movements significantly affect future exchange rate movements, but changes in exchange rates have less direct impacts on future changes of stock prices. The weak impact of exchange rate fluctuations on stock market returns may be explained by the effective hedging strategies against currency risks through available currency derivatives such as currency forwards, futures and options. Grant and Marshall (1997) suggest that the resort to financial hedging by multinational firms reduce the impact of exchange rate fluctuations on stock returns, given that the sensitivity of stock markets to exchange rate depends greatly on the exchange rate exposure of listed firms.

The effects of stock returns on exchange rate movements are captured by the coefficients $\beta_{31}$ and $\beta_{32}$ ). They are highly significant in the case of BRIC countries (Brazil, China, India, and Russia), but insignificant for South Africa. This finding thus supports the theoretical prediction of the stock-oriented models. This relationship is negative in both high and low volatility regimes for Brazil and India, suggesting that an increase in stock market returns leads to depreciate the respective exchange rates (i.e., the appreciation of the US dollar against the local currency). This result is consistent with the finding of Granger et al (2000), Hatemi-J and Roca (2005), Phylaktis and Ravazzolo (2005), and Pan et al (2007). ${ }^{4}$ Granger et al (2000) note for example that stock prices lead exchange rates with negative correlation in some Asian

\footnotetext{
${ }^{4}$ It is worth noting that these studies also use the nominal exchange rate as measured by the amount of US dollars per unit of local currency, except Phylaktis and Ravazzolo (2005) who consider real exchange rates.
} 
countries during the period of financial crisis of July 1997. Pan et al (2007) also examine the dynamic linkages between stock and foreign exchange markets for some Asian countries (Hong Kong, South Korea, and Singapore). Their results indicate that movements in exchange rates before the 1997 Asian financial crisis are, to some extent, driven by changes in stock prices. The stock-exchange rate link is also negative in the case of Russia for the high volatility regime.

Table 4 also reports the correlation coefficients between stock and exchange rate returns for the low and high volatility regimes. As we can see, they are all negative and their absolute values are higher during the high volatility regime than during the low volatility regime. Lin (2012) finds similar result for Asian emerging markets, according to which the correlation between foreign exchange and stock markets rose during crisis periods. This increased linkage can be interpreted as a contagion effect between asset prices.

All in all, our findings show that the stock prices in BRICS countries have some significant impact on the US dollar exchange rates, but the impact from exchange rates to stock market returns is not significant. They are thus of particular interest for portfolio investors and policy makers. First, it helps investors to better understand the dynamic relationship between the two financial markets in a business environment which is characterized by regime shifts and frequent changes. Capital budgeting decisions, and investment and risk hedging strategies in an international context involving the BRICS markets should take into account the stockexchange rate link, depending on whether the local markets are in normal or turbulent times. Second, policymakers should be aware of the presence of shock transmission between foreign exchange and stock markets when building an optimal strategy to preserve financial stability perspective in cases of crises. Finally, our empirical insights are also useful for central banks in the BRICS countries as the latter are responsible for monetary policy regulations and exchange rate regimes.

\section{Conclusion}

Past studies find evidence of interactions between stock and foreign exchange markets. In this article, we examine this intriguing issue for the BRICS countries in a regime-switching environment. We first use the Markov switching autoregressive model to detect regime-shift behavior in the stock returns of the BRICS markets, and find evidence to support the existence of two distinct regimes for all markets, a low volatility regime and a high volatility regime. 
Second, by considering the exchange rate volatility over two exceptional periods of major crises and important instabilities (the late 1990s and the late 2000s), we find that the US dollar exchange rates of the BRICS countries react differently to these major events, with the Chinese Yuan being mostly insensitive to the movements of the US dollar value. Finally, the extension of our empirical investigation to the dynamic linkages between stock and exchange rate returns via a MS-VAR model shows that exchange rate changes do not affect stock market returns of BRICS countries, regardless of the regimes. Inversely, the impact from stock market returns to exchange rates is significant for all countries, except South Africa, and it is more pronounced during the period of the high volatility. Investors, fund and portfolio managers, and policymakers should thus give heed to these regime-specific interactions when they make capital budgeting decisions and implement regulation policies.

\section{References}

Aloui, C., 2007. Price and volatility spillovers between exchange rates and stock indexes for the pre- and posteuro period. Quantitative Finance 7, 1-17.

Bekaert, G., Harvey, C.R., 1995. Time-varying world market integration. Journal of Finance 50, 403-444.

Branson, W., 1983. Macroeconomic determinants of real exchange risk. In R. J. Herring (eds.), "Managing Foreign Exchange Risk", Cambridge University Press.

Chan, K.F., Treepongkaruna, S., Brooks R., Gray S., 2011. Asset market linkages: Evidence from financial, commodity and real estate assets. Journal of Banking \& Finance 35, 1415-1426.

Chkili, W., Aloui, C., Masood, O., Fry, J., 2011. Stock market volatility and exchange rates in emerging countries: A Markov-state switching approach. Emerging Markets Review 12, 272-292.

Chkili, W., Nguyen, D.K., 2011. Modeling the volatility of Mediterranean stock markets: a regime-switching approach. Economic Bulletin 31, 1105-1113.

Coudert, V., Couharde, C., Mignon, V., 2011. Exchange rate volatility across financial crises. Journal of Banking \& Finance 35, 3010-3018.

Diamandis, P., Drakos, A., 2011. Financial liberalization, exchange rates and stock prices: exogenous shocks in four Latin America countries. Journal of Policy Modeling 33, 381-394.

Dornbusch, R., Fisher, S., 1980. Exchange rates and the current account. American Economic Review 70, 960971.

Frankel, J. A. (1983) Monetary and portfolio-balance models of exchange rate determination. In J.S. Bhandari and B. H. Putnam (eds.), "Economic Interdependence and Flexible Exchange Rates", 84-115, MIT Press: Cambridge.

Garcia, R., Perron, P., 1996. An analysis of the real interest rate under regime shifts. Review of Economics and Statistics 78,111-125.

Granger, C., Huang, B., Yang, C., 2000. A bivariate causality between stock prices and exchange rates: evidence from recent Asian flu. Quarterly Review of Economics and Finance 40, 337-354.

Grant, K., Marshall, A., 1997. Large UK companies and derivatives. European Financial Management 3, 191208. 
Hamilton, J.D., 1989. A new approach to the economic analysis of nonstationary time series and the business cycle. Econometrica 57, 357-384.

Hamilton, J.D., 1994. Time Series Analysis. Princeton: Princeton University Press.

Hatemi-J, A., Roca, E., 2005. Exchange rates and stock prices during good and bad times: evidence from the ASIAN 4 countries. Applied Financial Economics 15, 539-546.

Kanas, A., 2000. Volatility spillover between stock returns and exchange rate changes: International evidence. Journal of Business, Finance and Accounting 27, 447-467.

Kanas, A., 2005. Regime linkages between the Mexican currency market and emerging equity markets. Economic Modelling 22, 109-125.

Krolzig, H.M., 1997. Markov Switching Autoregressive: modeling statistical inference and application to business cycles analysis. Springer, Berlin.

Krolzig, H.-M., 2000. Predicting Markov-switching vector autoregressive processes. Nuffield College Economics Working Papers, 2000-WP31.

Lin, C-H, 2012. The comovement between exchange rates and stock prices in the Asian emerging markets. International Review of Economics and Finance 22, 161-172.

Pan, M.S., Fok, R.C.-W., Liu, Y.A., 2007. Dynamic linkages between exchange rates and stock prices: evidence from East Asian markets. International Review of Economics and Finance 16, 503-520.

Phylaktis, K., Ravazzolo, F., 2005. Stock prices and exchange rate dynamics. Journal of International Money and Finance 24, 1031-1053.

Wang, P., Theobald, M., 2008. Regime-switching volatility of six East Asian emerging markets. Research in International Business and Finance 22, 267-283.

Yang, S.Y., Doong, S.C., 2004. Price and volatility spillovers between stock prices and exchange rates: empirical evidence from the G-7 countries. International Journal of Business and Economics 3, 139-153. 